\title{
Prediction of design parameters of pneumatic cleaners with MARS method
}

\author{
Ali Tekgüler ${ }^{1 *}$, Emre Dünder ${ }^{2}$, Tuğba Karaköse ${ }^{3}$ \\ (1. Department of Agricultural Machinery, Samsun Vocational School, Ondokuz Mayls University, Illkadım, Samsun 55070, Turkey; \\ 2. Statistics Department, Faculty of Science-Literature, Ondokuz Mayis University, Atakum, Samsun 55200, Turkey; \\ 3. Department of Agricultural Machinery and Technologies Engineering, Faculty of Agriculture, Ondokuz Mayis University, \\ Atakum, Samsun 55200, Turkey)
}

\begin{abstract}
One of the cleaning methods for agricultural materials is based on aerodynamic properties. Pneumatic cleaners are developed on this method. The purpose of this study is to predict the parameters such as fan angle, air velocity, and tunnel length, which are used in the design of pneumatic cleaners, through the multivariate adaptive regression splines (MARS) method. Some parameters have been estimated using the MARS method in order to use pneumatic cleaners under optimum conditions and adapt them to automation systems. The cleaners have a collection box which was installed at the outlet of the storage. Two different product collection boxes of $400 \mathrm{~mm}$ (defined as the first box) and $800 \mathrm{~mm}$ (defined as the second box) from the storage outlet section were used. From the results obtained, it was observed that the first box $R^{2}$ was higher. When looking at the cross validation, it was observed that the results of the first box were more acceptable. With this study, MARS equations were used to obtain dependent variables at desired values. Using these equations, independent variables have been demonstrated to be identifiable. In the application results obtained, cleaning efficiency values were obtained in a wide range. While cleaning efficiency values reached up to $100 \%$, the loss rate was found to be very high. Independent variables have been made identifiable to reduce the loss rate. The highest and feasible of these values were determined by MARS as $41^{\circ}$ fan angle and $15 \mathrm{~m} / \mathrm{s}$ air velocity in order to be able to apply at $97 \% \mathrm{CE}$ and $1 \%$ LR determined for the first box. The MARS method allows for the use of more dependent and independent variables. Usable equations were obtained as a result of statistical analysis. More precise values can be obtained with these equations. It will contribute to the design of the parameters of the machine manufactured, such as speed, angle, and feeding amount.
\end{abstract}

Keywords: MARS, pneumatic cleaner, cleaning efficiency, loss ratio

DOI: $10.25165 /$ j.ijabe.20211402.5715

Citation: Tekgüler A, Dünder E, Karaköse T. Prediction of design parameters of pneumatic cleaners with MARS method. Int J Agric \& Biol Eng, 2021; 14(2): 106-111.

\section{Introduction}

In order to become useable, agricultural products should undergo a series of processes such as cleaning, classifying, drying and storing. Useable grains are cleaned by applying the process of separating from other materials. One of the cleaning methods is based on aerodynamic characteristics, which makes use of different relative speeds of the grains within the airflow ${ }^{[1]}$. Pneumatic cleaners are developed on this method. Pneumatic cleaners basically consist of air tunnel and air flow producer (fan). These cleaners work on the basis of absorbing or pressing air into tunnel.

Cleaning according to aerodynamic characteristics, different relative speeds of grains are made use of within the air flow. The process of separation is conducted in vertical and horizontal air tunnels. In horizontal air tunnel, the air is blown horizontally or

Received date: 2020-02-04 Accepted date: 2020-04-26

Biographies: Emre Dünder, PhD, Associate Professor, research interest: probability theory, Applied Mathematics, Statistics, Email: emre.dunder@ omu.edu.tr; Tuğba Karaköse, $\mathrm{PhD}$ candidate, research interest: agricultural machinery, product cleaning technology, sowing and tillage, Email: tugba.karakose@omu.edu.tr.

*Corresponding author: Ali Tekgüler, PhD, Associate Professor, research interest: agricultural machinery, product cleaning technology, sowing and tillage. Department of Agricultural Machinery, Samsun Vocational School, Ondokuz Mayıs University, İlkadım, Samsun 55070, Turkey. Tel: +90-5437728592, Email: atekgul@omu.edu.tr. with a slope on the mixture going through the vertical plane. Along the horizontal air tunnel, the mixture is scattered along different distances based on aerodynamic characteristics ${ }^{[2]}$. Mathematical models are used in cleaning processes and determining parameters. By creating mathematical models, the time and cost of test is decreased, basic relationships are better understood, simulation models are built and the effects of different parameters and possible performance increase are predicted and clues are given for improvement ${ }^{[3]}$. One of the mathematical modelling methods is multivariate adaptive regression splines (MARS). MARS method was developed by physicist and statistician $^{[4]}$. This model is used to analyze the effect of independent variables on the dependent variable. In MARS method, the model is formed in two stages. First, existing variables are used and all possible functions are generated. These functions are called basic functions. One of the most important advantages of this method is the fact that it turns the non-linear relationship between independent variables into linear relationship. In the method, it is possible to give different coefficients for different values of the dependent variable. For this reason, MARS method reflects the relationships between variables better, which enables MARS system to get ahead of others statistical models ${ }^{[5]}$. MARS is one of the methods which use validity analysis in testing the accuracy of a model. Cross-validation test is used in case of limited number of data ${ }^{[6]}$.

The purpose of this study is to predict the parameters such as 
fan angle, air velocity and tunnel length, which are used in the design of pneumatic cleaners, through MARS method.

\section{Materials and methods}

Experiments were conducted with corn (Zea mays var. indedata Sturt.) grains and their cobs. The corn cobs were crashed by the hammer mill to reduce the size. During the course of the experiment, the grain moisture varied between 15\%-16\%. Experimental setup used by Karaköse et al. ${ }^{[7]}$ was adopted.

Feed rate of $1600 \mathrm{~kg} / \mathrm{h}$ were performed. Air velocities were set to $15,18,21,24$ and $27 \mathrm{~m} / \mathrm{s}$. The horizontal angles of the fan can be adjusted to $15^{\circ}, 30^{\circ}$ and $45^{\circ}$ with the test mechanism. A mixture of $8 \mathrm{~kg}$ was prepared, of which $90 \%$ as corn and $10 \%$ as corncob, $85 \%$ as corn and $15 \%$ as corncob, $80 \%$ as corn and $20 \%$ as corncob was arranged. When designing agricultural machinery, it is expected to fully function. In addition, it should be economical, ergonomic, producible, environmentally friendly, recyclable and developable. The machine can carry through its function with different designs. In this case, the optimum design should be chosen. It was designed by considering many factors. One of them is product collection boxes length. During the design, the machine was tried to be made smaller and useful. Additionally, the product collection boxes were designed in different lengths to produce and operate economically. Preliminary tests were conducted to determine the length of the product collection boxes. As a result of these trials, a collection box, all $800 \mathrm{~mm}$, was installed at the outlet of the storage. Two different product collection boxes of $400 \mathrm{~mm}$ and $800 \mathrm{~mm}$ from storage outlet section were used. The first collecting box is 400 $\mathrm{mm}$ and the second collecting box is $800 \mathrm{~mm}$.

The product cleaning efficiency and loss ratio of grain-cob quantities were determined using the following equations ${ }^{[8]}$.

$$
C E=\left(\frac{G_{0}}{G_{1}}\right) \times 100 \%
$$

where, $C E$ represents cleaning efficiency, \%; $G_{0}$ represents the weight of grain at outlet, $\mathrm{kg} ; G_{1}$ represents total mixture weight at outlet, $\mathrm{kg}$.

$$
L R=\left(\frac{G_{i}}{G_{w}}\right) \times 100 \%
$$

where, $L R$ represents rate of grain loss in cleaning units, \%; $G_{i}$ represents weight of grain threw out of the air tunnel per feeding unit, $\mathrm{kg}$; $G_{w}$ represents grain weight in the mixture per feeding unit, $\mathrm{kg}$.

Each application of 3 different mixture rates, 5 different air

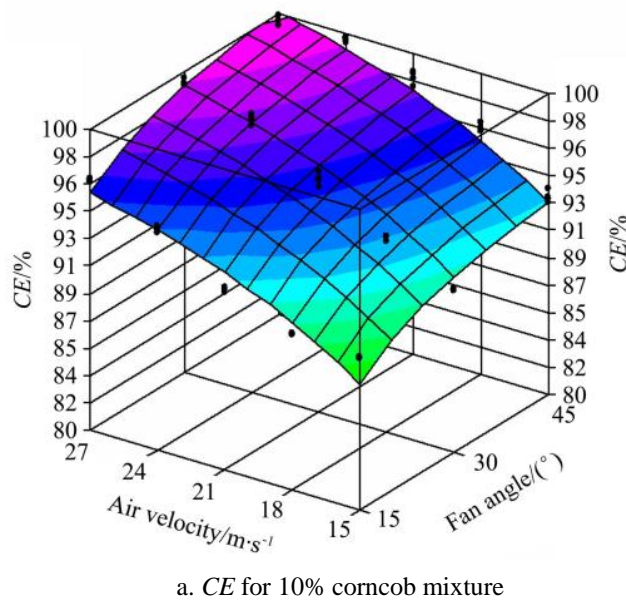

Note: black dots represent the actual values. velocities and 3 different fan angles were made four repetitions.

MARS is a nonparametric modelling method that avoids the linearity assumption between explanatory and dependent variables. It was developed by Friedman ${ }^{[4]}$. The general relational form is shown as follows:

$$
Y=f\left(X_{1}\right)+f\left(X_{2}\right)+\ldots+f\left(X_{p}\right)+\varepsilon
$$

where, $X=\left(X_{1}, X_{2}, \ldots X_{P}\right)$ represents the explanatory variables set; $Y$ represents the dependent variable and $\varepsilon$ indicates the residuals of the model. Also it is possible to include two or more dependent variables with MARS. MARS algorithm uses the basic functions (BF) to represent $f($.) functions. MARS algorithm constructs a model as follows:

$$
Y=\beta_{0}+\sum_{k=1}^{p} \beta_{k} B F_{k}\left(X_{k}\right)+\varepsilon
$$

where, $\beta_{0} \ldots \beta_{k}$ represent the regression coefficients of MARS.

As it is seen in Equation (4) MARS is very similar to classical regression model. The main difference from the classical regression model is to use splines via BFs. MARS algorithm selects the knot points between two adjacent splines. Knots provide the continuity of the $\mathrm{BFs}^{[9]}$. The selection of the optimal knot is performed with a selection algorithm and goodness of fit test. Backward stepwise algorithm and generalized cross validation (GCV) is generally used as the selection algorithm and goodness of fit test, respectively. Backward stepwise algorithm struggles to minimize GCV value so as to exclude the BFs that give smallest contribution to the model at each stage ${ }^{[10]}$.

The GCV measure is defined as:

$$
G C V=\sum_{i=1}^{n} \frac{\varepsilon_{i}^{2}}{(1-D(m))^{2}}
$$

where, $\varepsilon_{i}^{2}$ is the residual squares for $i=1,2, \ldots, n ; n$ is an infinite value; $D(m)$ is a penalty term, which depends on the BFs of estimated MARS model; $\mathrm{m}$ is input value.

\section{Results and discussion}

The mixtures are drifted to different lengths due to air velocity and fan angle based on the characteristics of these materials. For this reason, two collecting boxes at different lengths were used.

For the first collecting box, $C E$ differed between $80.07 \%$ $99.86 \%$, while $L R$ differed between $0.73 \%-94.58 \%$. For $10 \%$ corncob mixture, $C E$ values were between $90.07 \%-99.86 \%$, while $L R$ values were between $0.76 \%-94.58 \%$. The highest $C E$ value was obtained $(99.86 \%)$ at $45^{\circ}$ fan angle and $27 \mathrm{~m} / \mathrm{s}$ air velocity, while the lowest LR value was found $(0.76 \%)$ at $30^{\circ}$ fan angle and $15 \mathrm{~m} / \mathrm{s}$ air velocity (Figure 1).

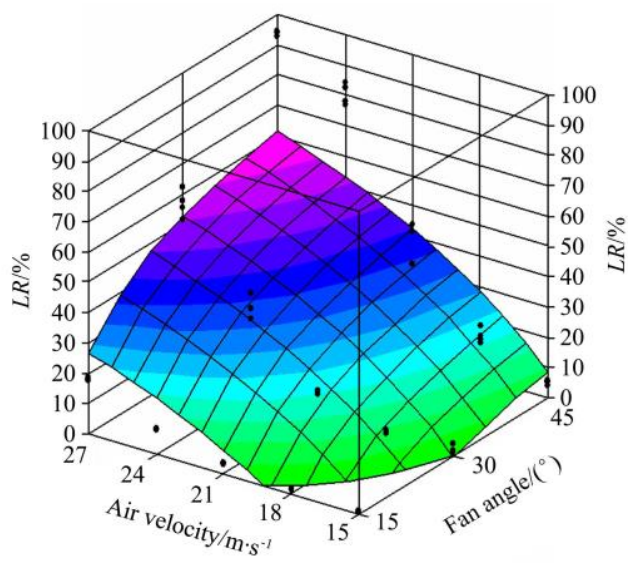

b. $L R$ for $10 \%$ corncob mixture

Figure $1 C E$ and $L R$ changes over air velocity and fan angle for the first collecting box and $10 \%$ corncob mixture 
For $15 \%$ corncob mixture, $C E$ values were between $85.29 \%$ $99.78 \%$, while $L R$ differed between $0.73 \%-93.65 \%$. The highest $C E$ value was measured $\left(99.78 \%\right.$ ) at $45^{\circ}$ fan angle and $27 \mathrm{~m} / \mathrm{s}$ air velocity, while the lowest $L R$ value was found $(0.73 \%)$ at $15^{\circ}$ fan angle and $15 \mathrm{~m} / \mathrm{s}$ air velocity (Figure 2 ).

For $20 \%$ corncob mixture, $C E$ values were between $80.07 \%$ $99.46 \%$, while $L R$ differed between $0.81 \%-91.48 \%$. The highest $C E$ value was measured $(99.46 \%)$ at $45^{\circ}$ fan angle and $24 \mathrm{~m} / \mathrm{s}$ air velocity, while the lowest $L R$ value was found $(0.81 \%)$ at $15^{\circ}$ fan angle and $15 \mathrm{~m} / \mathrm{s}$ air velocity (Figure 3 ).

In previous studies, $C E$ values were found as $42.00 \%-80.00 \%$

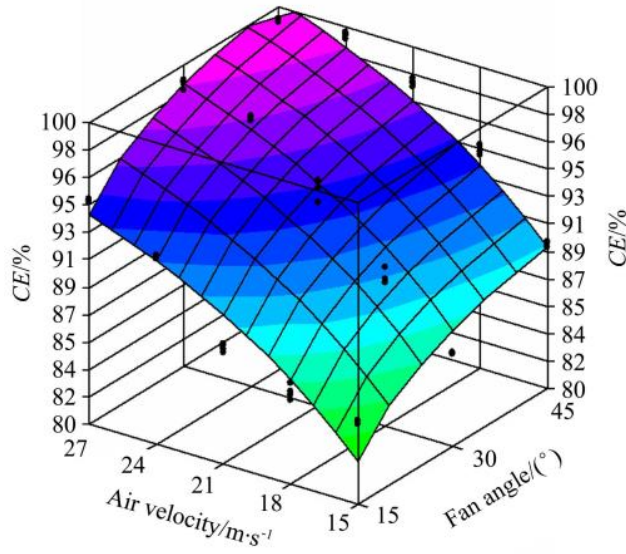

a. $C E$ for $10 \%$ corncob mixture

Note: black dots represent the actual values. in $\operatorname{corn}^{[11]}, 99.85 \%$ in sorghum ${ }^{[8]}, 80.00 \%$ in oat, $94.00 \%$ in wheat and $98.00 \%$ in rye ${ }^{[12]}, 93.00 \%$ in chickpea ${ }^{[13]}$ and $87.20 \%$ in amulet lupine ${ }^{[14]}$.

For the second collecting box, $C E$ differed between $80.03 \%$ $98.67 \%$, while $L R$ differed between $0.12 \%-73.63 \%$. For $10 \%$ corncob mixture, $C E$ values were between $90.02 \%-98.67 \%$, while $L R$ values were between $0.21 \%-73.63 \%$. The highest $C E$ value was obtained $(98.67 \%)$ at $45^{\circ}$ fan angle and $27 \mathrm{~m} / \mathrm{s}$ air velocity, while the lowest $L R$ value was found $(0.21 \%)$ at $15^{\circ}$ fan angle and $15 \mathrm{~m} / \mathrm{s}$ air velocity (Figure 4 )

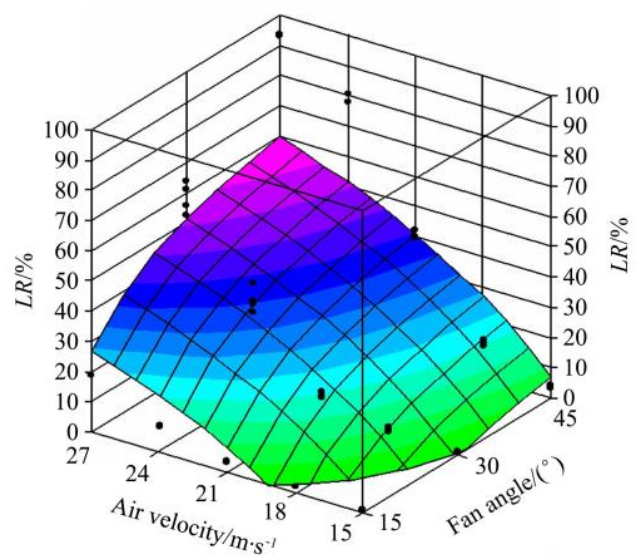

b. $L R$ for $10 \%$ corncob mixture

Figure $2 C E$ and $L R$ changes over air velocity and fan angle for the first collecting box and $15 \%$ corncob mixture

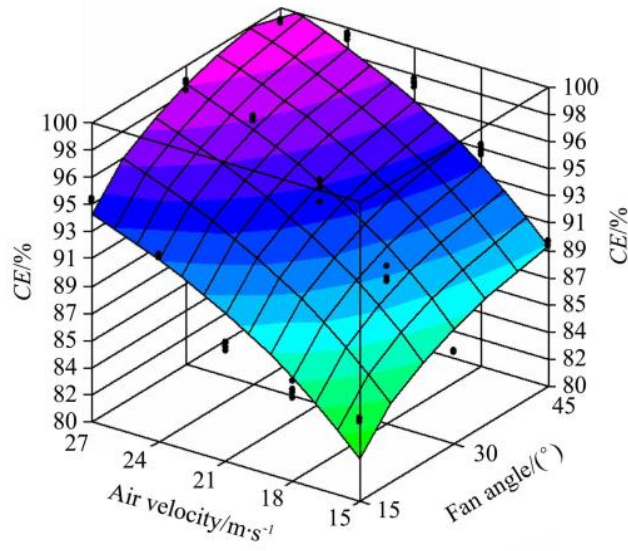

a. $C E$ for $10 \%$ corncob mixture

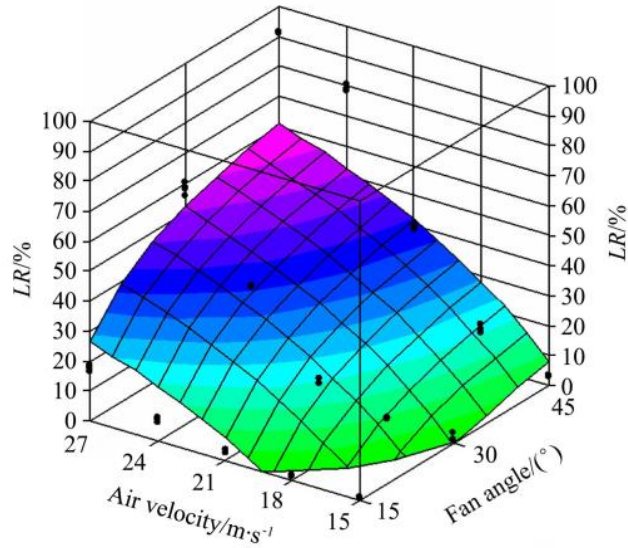

b. $L R$ for $10 \%$ corncob mixture

Note: black dots represent the actual values.

Figure $3 C E$ and $L R$ changes over air velocity and fan angle for the first collecting box and $20 \%$ corncob mixture

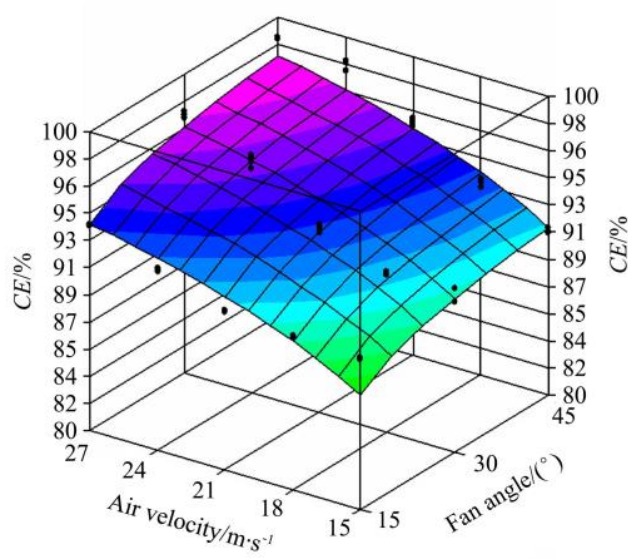

a. $C E$ for $10 \%$ corncob mixture

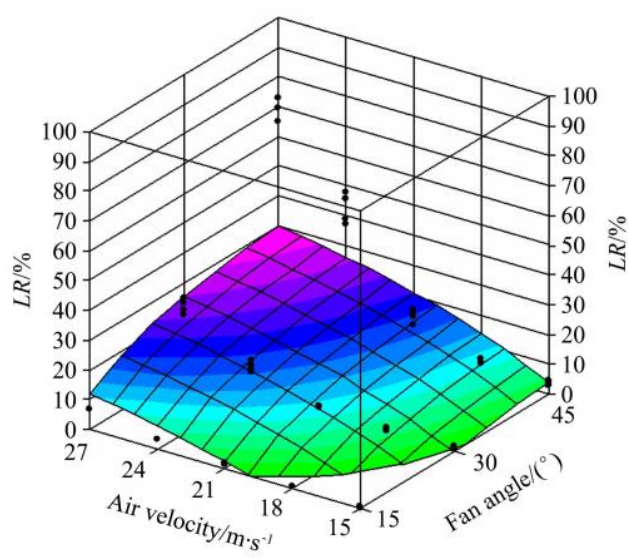

b. $L R$ for $10 \%$ corncob mixture

Note: black dots represent the actual values.

Figure $4 C E$ and $L R$ changes over air velocity and fan angle for the second collecting box and $10 \%$ corncob mixture 
For $15.00 \%$ corncob mixture, $C E$ values were between 84.94\%-98.65\%, while $L R$ differed between $0.12 \%-70.29 \%$. The highest $C E$ value was measured $(98.65 \%)$ at $45^{\circ}$ fan angle and $27 \mathrm{~m} / \mathrm{s}$ air velocity, while the lowest $L R$ value was found $(0.12 \%)$ at $15^{\circ}$ fan angle and $15 \mathrm{~m} / \mathrm{s}$ air velocity (Figure 5).

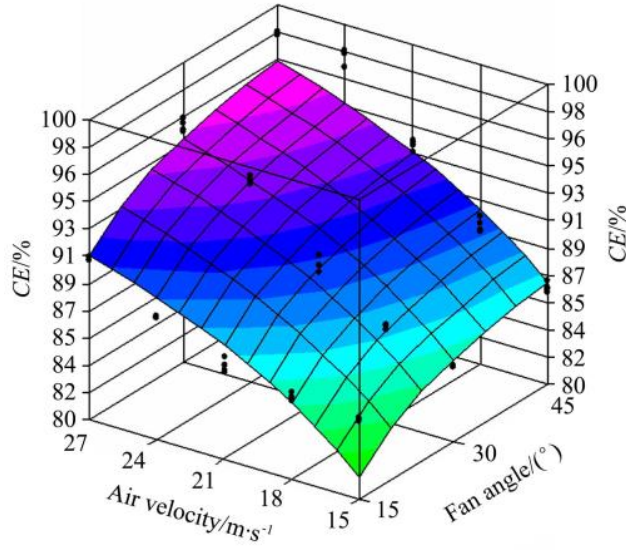

a. $C E$ for $10 \%$ corncob mixture

Note: black dots represent the actual values.
For $20 \%$ corncob mixture, $C E$ values were between $80.03 \%$ $98.11 \%$, while $L R$ differed between $0.32 \%-65.61 \%$. The highest $C E$ value was measured $(98.11 \%)$ at $45^{\circ}$ fan angle and $27 \mathrm{~m} / \mathrm{s}$ air velocity, while the lowest $L R$ value was found $(0.32 \%)$ at $15^{\circ}$ fan angle and $15 \mathrm{~m} / \mathrm{s}$ air velocity (Figure 6).

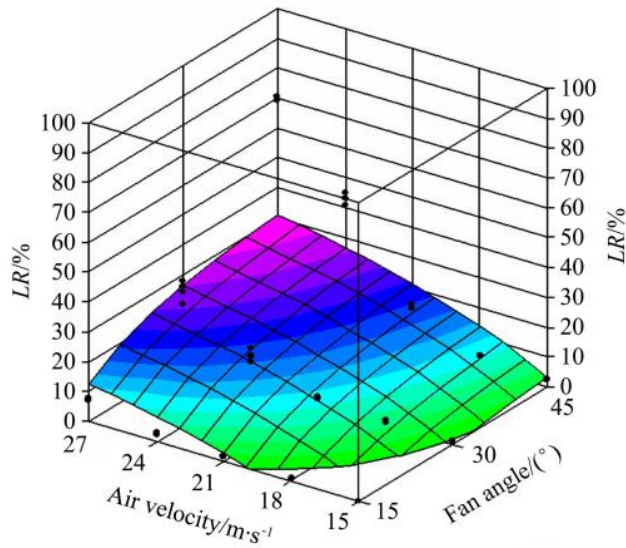

b. $L R$ for $10 \%$ corncob mixture

Figure $5 C E$ and $L R$ changes over air velocity and fan angle for the second collecting box and $15 \%$ corncob mixture

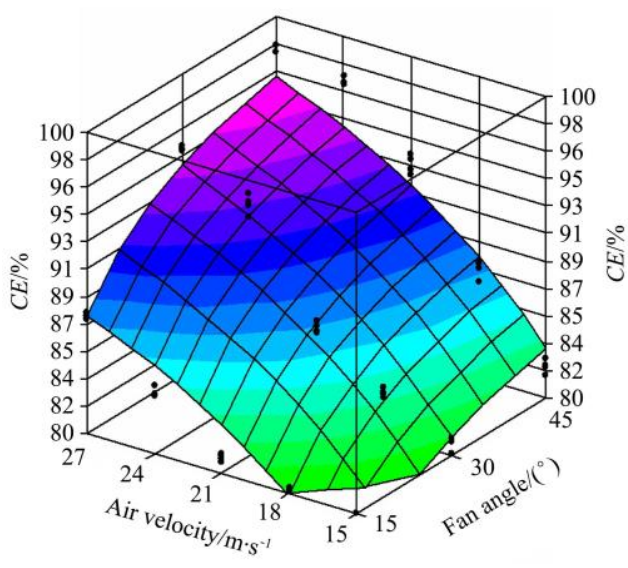

a. $C E$ for $10 \%$ corncob mixture

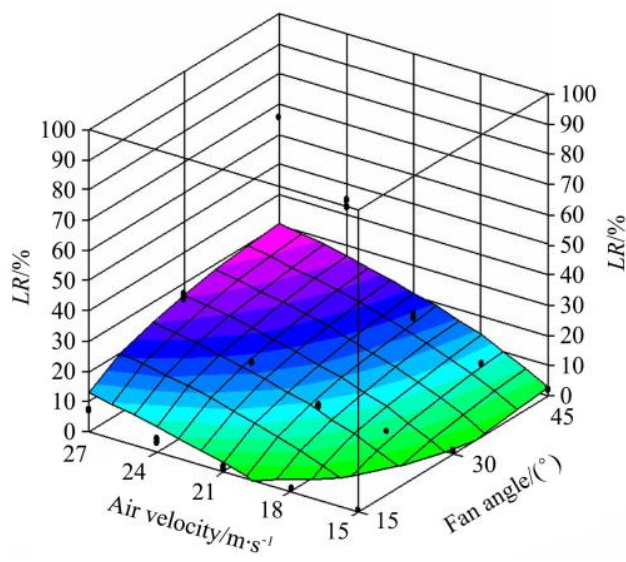

b. $L R$ for $10 \%$ corncob mixture

Note: black dots represent the actual values.

Figure $6 C E$ and $L R$ changes over air velocity and fan angle for the second collecting box and $20 \%$ corncob mixture

Both $C E$ and $L R$ values in the first box were found to be higher when comparing with that of the second box.

For the first collecting box, the highest $C E$ value (99.86\%) was found in $10 \%$ mixture ratio, $45^{\circ}$ fan angle and $27 \mathrm{~m} / \mathrm{s}$ air velocity, while the lowest $C E$ value $(80.07 \%)$ was found in $20 \%$ mixture ratio, $15^{\circ}$ fan angle and $15 \mathrm{~m} / \mathrm{s}$ air velocity.

For the second collecting box, the highest $C E$ value (98.67\%) was found in $10 \%$ mixture ratio, $45^{\circ}$ fan angle and $27 \mathrm{~m} / \mathrm{s}$ air velocity, while the lowest $C E$ value $(80.03 \%)$ was found in $20 \%$ mixture ratio, $15^{\circ}$ fan angle and $15 \mathrm{~m} / \mathrm{s}$ air velocity.

For the first collecting box, the highest $L R$ value $(94.58 \%)$ was found in $10 \%$ mixture ratio, $45^{\circ}$ fan angle and $27 \mathrm{~m} / \mathrm{s}$ air velocity, while the lowest $L R$ value $(0.73 \%)$ was found in $15 \%$ mixture ratio, $15^{\circ}$ fan angle and $15 \mathrm{~m} / \mathrm{s}$ air velocity.

For the second collecting box, the highest $L R$ value (73.63\%) was found in $10 \%$ mixture ratio, $45^{\circ}$ fan angle and $27 \mathrm{~m} / \mathrm{s}$ air velocity, while the lowest $L R$ value $(0.12 \%)$ was found in $15 \%$ mixture ratio, $15^{\circ}$ fan angle and $15 \mathrm{~m} / \mathrm{s}$ air velocity. It was found that the increase in the length of air tunnel in which cleaned products were taken from the feed outlet caused a decrease in product loss.

Up to $54.00 \%$ loss was found in sorghum ${ }^{[8]}$. Uhl and Lamp ${ }^{[12]}$ stated that it would not be possible to clean corn without loss of grain.

In this study, we implemented cross-validation for testing the performance of constructed MARS models. For each dependent variable, we split the data set as train and test with $70 \%$ and $30 \%$. This process was repeated for 500 times. The error percentages were calculated for every step for mixture ratio, fan angle, and air velocity. The error percentage formula is calculated as follows:

$$
\text { error percentage }=100 \% \times \sum_{i=1}^{n}\left|\frac{Y_{i}-Y_{i(\text { pred })}}{Y_{i(\text { pred })}}\right|
$$

where, $Y_{i}$ shows the actual values and $Y_{i(p r e d)}$ denotes the predicted values.

Generalized R-Squared (GRSq) is calculated as 1-GCV/gcv.null, where GRSq is an estimate of the predictive power of the MARS model; GCV is the information criterion value and the smaller one is preferred; gcv.null means the GCV coefficient of the empty model, that is, the GCV value of the model in the absence of variables. $R^{2}$ is calculated as (1-RSS/GSS), where RSS is residual sum of squares and GSS is general sum of squares.

Figure 7 shows the percentage of errors of each dependent variable for the first box. According to plots, the errors converge 
to specific values for the first box's MARS model. The average percentage errors of dependent variables are approximately $17.80 \%$,
$27.10 \%$ and $8.00 \%$ for mixture ratio, fan angle and air velocity, respectively.

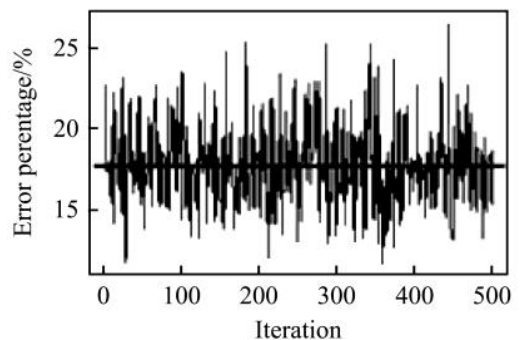

a. Mixture

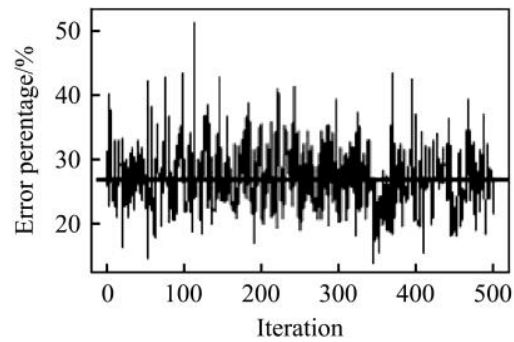

b. Angle

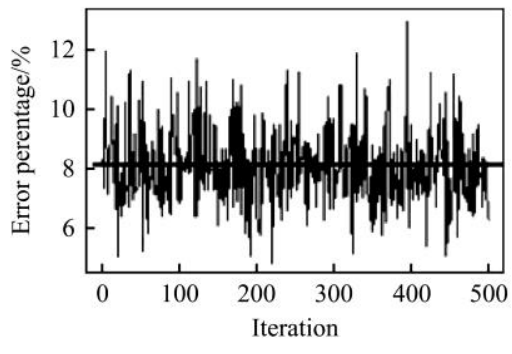

c. Speed

Figure 7 Cross validation plots of each dependent variable for the first box

The obtained MARS equations for the first box are given: Mixture $=26.8399-2.300392 \times \max (0, C E-89.53534)$ $+7.106377 \times \operatorname{pmax}(0, C E-92.08448)$ $-7.406227 \times p \max (0, C E-93.12541)$ $-0.08622167 \times p \max (0, C E-94.25177)$ $+0.6545416 \times \operatorname{pmax}(0,96.44607-C E)$ $+0.1807471 \times \operatorname{pmax}(0, L R-8.416912)$ $-1.259169 \times \max (0, L R-12.28562)$ $-0.9929379 \times \operatorname{pmax}(0,18.68676-L R)$ $+1.575021 \times \operatorname{pmax}(0, L R-18.68676)$ $-0.4706188 \times \operatorname{pmax}(0, L R-39.95531)$ $-0.001130425 \times \max (0, L R-55.75531)$

Angle $=25.18553-7.804487 \times \operatorname{pmax}(0, C E-89.53534)$ $+33.02789 \times \operatorname{pmax}(0, C E-92.08448)$ $-36.91635 \times \max (0, C E-93.12541)$ $+12.38012 \times \operatorname{pmax}(0, C E-94.25177)$ $-1.496044 \times \operatorname{pmax}(0,96.44607-C E)$ $+6.736533 \times \operatorname{pmax}(0, L R-8.416912)$ $-11.54101 \times \operatorname{pmax}(0, L R-12.28562)$ $+0.8893408 \times \operatorname{pmax}(0,18.68676-L R)$ $+6.070865 \times \operatorname{pmax}(0, L R-18.68676)$ $-2.134233 \times \max (0, L R-39.95531)$ $+1.321696 \times \operatorname{pmax}(0, L R-55.75531)$

Velocity $=34.13918+1.002477 \times \operatorname{pmax}(0, C E-89.53534)$

$-5.036817 \times \operatorname{pmax}(0, C E-92.08448)$ $+5.254268 \times \operatorname{pmax}(0, C E-93.12541)$ $-1.571007 \times \operatorname{pmax}(0, C E-94.25177)$ $+0.1113256 \times \operatorname{pmax}(0,96.44607-C E)$ $-2.513273 \times \operatorname{pmax}(0, L R-8.416912)$ $+3.077915 \times \max (0, L R-12.28562)$ $-1.099261 \times \operatorname{pmax}(0,18.68676-L R)$ $-0.8025444 \times \operatorname{pmax}(0, L R-18.68676)$ $+0.5707227 \times \operatorname{pmax}(0, L R-39.95531)$ $-0.3410949 \times \operatorname{pmax}(0, L R-55.75531)$

In the equations, $\operatorname{pmax}($.$) represents the maximum element$ value of the pair.

Table 1 represents the performance metrics of the first box's MARS model. The $R^{2}$ value of the model is approximately 0.67 , which means the model can explain $67 \%$ variance of the dependent variables. The model has moderate predictive power since $R^{2}$ is between [0.5, 0.7). In the first MARS model, the speed variable has the highest $R^{2}$ value though the second model can predict the mixture variable best.

Figure 8 shows the percentage of errors of each dependent variable for the second box. According to plots, the errors converge to specific values for the second box's MARS model. The average percentage errors of dependent variables are approximately $12.80 \%, 32.10 \%$ and $10.30 \%$ for mixture ratio, fan angle and air velocity, respectively.

Table 1 Performance metrics of the first collecting box's MARS model

\begin{tabular}{cccc}
\hline Variable & RSS & GRSq & $R^{2}$ \\
\hline Mixture & 1169.21540 & 0.34014 & 0.52756 \\
Angle & 7158.72900 & 0.53710 & 0.66858 \\
Speed & 351.49260 & 0.80990 & 0.86389 \\
All & 8679.43700 & 0.54525 & 0.67441 \\
\hline
\end{tabular}

The obtained MARS equations for the second box's model are given:

Mixture $=31.71104-1.04533 \times \operatorname{pmax}(0, C E-82.18299)$

$+2.492454 \times \operatorname{pmax}(0, C E-85.84755)$

$+0.2124251 \times \operatorname{pmax}(0,86.37032-C E)$

$-2.992835 \times \operatorname{pmax}(0, C E-86.37032)$

$+1.009478 \times \max (0, C E-90.26563)$

$-2.2557 \times \operatorname{pmax}(0, C E-92.57279)$

$-1.118565 \times \operatorname{pmax}(0, L R-10.49516)$

$-1.093839 \times \operatorname{pmax}(0,12.70953-L R)$

$+1.641191 \times \operatorname{pmax}(0, L R-12.70953)$

$-0.2106912 \times \max (0, L R-23.12736)$

$-0.3009597 \times \operatorname{pmax}(0, L R-40.70118)$

Angle $=70.19094-14.16677 \times \operatorname{pmax}(0, C E-82.18299)$

$+44.57863 \times \operatorname{pmax}(0, C E-85.84755)$

$-9.08579 \times \operatorname{pmax}(0,86.37032-C E)$

$-34.35611 \times \operatorname{pmax}(0, C E-86.37032)$

$+8.888801 \times \operatorname{pmax}(0, C E-90.26563)$

$-5.19328 \times \operatorname{pmax}(0, C E-92.57279)$

$+6.889248 \times \operatorname{pmax}(0, L R-10.49516)$

$+0.2382852 \times \max (0,12.70953-L R)$

$-8.552848 \times \operatorname{pmax}(0, L R-12.70953)$

$+2.728597 \times \operatorname{pmax}(0, L R-23.12736)$

$-1.082189 \times \operatorname{pmax}(0, L R-40.70118)$

Velocity $=30.9955-0.4613104 \times \operatorname{pmax}(0, C E-82.18299)$

$-1.002507 \times \operatorname{pmax}(0, C E-85.84755)$

$-0.5258183 \times \operatorname{pmax}(0,86.37032-C E)$

$+1.585862 \times \operatorname{pmax}(0, C E-86.37032)$

$-0.3739754 \times p \max (0, C E-90.26563)$

$+0.1863912 \times \operatorname{pmax}(0, C E-92.57279)$

$-3.454274 \times \operatorname{pmax}(0, L R-10.49516)$

$-0.934352 \times \operatorname{pmax}(0,12.70953-L R)$

$+4.160783 \times \max (0, L R-12.70953)$

$-0.9472505 \times \max (0, L R-23.12736)$

$+0.3632364 \times \operatorname{pmax}(0, L R-40.70118)$

where, $\operatorname{pmax}($.$) represents the maximum element value of the pair.$

Table 2 represents the performance metrics of the second box's MARS model. The $R^{2}$ value of the general model is approximately 0.57 . The model can explain $57 \%$ variance of the 
dependent variables. The second box's model has moderate predictive power since $R^{2}$ is between $[0.5,0.7)$. In the second
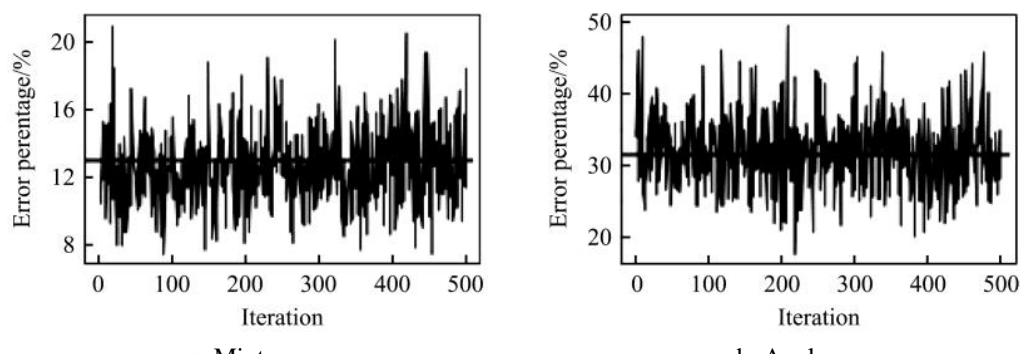

b. Angle box's MARS model, the model of mixture rate has the highest $R^{2}$ value so the model can predict the mixture rate best.

Figure 8 Cross validation plots of each dependent variable for the second box

Table 2 Performance metrics for the second collecting box's MARS model

\begin{tabular}{cccc}
\hline Variable & RSS & GRSq & $R^{2}$ \\
\hline Mixture & 647.99820 & 0.66078 & 0.74080 \\
Angle & 10121.40520 & 0.38515 & 0.53019 \\
Speed & 746.41210 & 0.62910 & 0.71660 \\
All & 11515.81550 & 0.43506 & 0.56833 \\
\hline
\end{tabular}

As a result of the MARS equations formed, the examples of dependent and independent variable values are given in Table 3.

Table 3 Estimated values with MARS equations

\begin{tabular}{|c|c|c|c|c|c|}
\hline \multicolumn{3}{|c|}{ First box } & \multicolumn{3}{|c|}{ Second box } \\
\hline & Parameter & $\begin{array}{l}\text { Estimated } \\
\text { value }\end{array}$ & & Parameter & $\begin{array}{l}\text { Estimated } \\
\text { value }\end{array}$ \\
\hline \multirow{3}{*}{$\begin{array}{c}C E=97 \% \\
L R=1 \%\end{array}$} & Mixture/\% & 2 & \multirow{3}{*}{$\begin{array}{c}C E=99 \% \\
L R=0 \%\end{array}$} & Mixture/\% & 1 \\
\hline & Fan angle $/\left({ }^{\circ}\right)$ & 41 & & Fan angle $/\left({ }^{\circ}\right)$ & 17 \\
\hline & Air velocity $/ \mathrm{m} \cdot \mathrm{s}^{-1}$ & 15 & & Air velocity $/ \mathrm{m} \cdot \mathrm{s}^{-1}$ & 16 \\
\hline \multirow{3}{*}{$\begin{array}{c}C E=95 \% \\
L R=0 \%\end{array}$} & Mixture/\% & 5 & \multirow{3}{*}{$\begin{array}{c}C E=98 \% \\
L R=0 \%\end{array}$} & Mixture/\% & 2 \\
\hline & Fan angle $/\left({ }^{\circ}\right)$ & 42 & & Fan angle $/\left({ }^{\circ}\right)$ & 23 \\
\hline & Air velocity $/ \mathrm{m} \cdot \mathrm{s}^{-1}$ & 15 & & Air velocity $/ \mathrm{m} \cdot \mathrm{s}^{-1}$ & 17 \\
\hline \multirow{3}{*}{$\begin{array}{c}C E=95 \% \\
L R=0 \%\end{array}$} & Mixture/\% & 8 & \multirow{3}{*}{$\begin{array}{c}C E=95 \% \\
L R=1 \%\end{array}$} & Mixture/\% & 5 \\
\hline & Fan angle $/\left(^{\circ}\right)$ & 41 & & Fan angle $/\left({ }^{\circ}\right)$ & 23 \\
\hline & Air velocity $/ \mathrm{m} \cdot \mathrm{s}^{-1}$ & 15 & & Air velocity $/ \mathrm{m} \cdot \mathrm{s}^{-1}$ & 17 \\
\hline
\end{tabular}

\section{Conclusions}

With this study, MARS equations are used to obtain dependent variables at desired values. Using these equations, independent variables have been demonstrated to be identifiable. In the application results obtained, cleaning efficiency values were obtained in a wide range. While cleaning efficiency values reached up to $100 \%$, the loss rate was found to be very high. Independent variables have been made identifiable to reduce the loss rate. The highest and feasible of these values are determined by MARS as $41^{\circ}$ fan angle and $15 \mathrm{~m} / \mathrm{s}$ air velocity in order to get 97\% CE and $1 \% L R$ for the first box.

From the results obtained, it was observed that the $\mathrm{R}^{2}$ of the model for the first box was higher. When looking at the cross validation, it was observed that the results of the first box were more acceptable. However, the results for the first and the second box were still close to each other. In addition, according to the results obtained with the MARS equations, when two dependent variables were kept unchanged, independent variables could be determined. The machine to be manufactured can be turned into a fully controllable machine with an automation system.

In accordance with these results and machine design parameters, the first collecting box is considered more suitable because it is shorter and more useful. Thus, the machine manufactured as a prototype can be made smaller and useful. It will be able to contribute to the design of parameters in terms of developing ability of this machine. However, the whole range of possible influences has to be investigated further. It will be useful to test the values obtained with mixture ratio, fan angle and air velocity equations by automation applications. It will contribute to the development of pneumatic harvesting and cleaning machines. In order to use it more efficiently and effectively, it will be contributed to the development of the machine by trying the trials on different products and using more sensitive parameters.

\section{[References]}

[1] Berber S. Determination of aerodynamic properties of safflower (Carthamus tinctorious L.) seeds. Master dissertation. Tokat: Gaziosmanpaşa University, 2007. (in Turkish)

[2] Adewumi B A, Ademosun O C, Ogunlowo A S. Preliminary investigation on the distribution and spread pattern of cowpea in a cross flow grain separator. Agricultural Engineering International: The CIGR Ejournal, 2006; VIII: 1-12.

[3] Kutzbach H D. Approaches for mathematical modelling of grain separation. Proceedings of the International Conference on Crop Harvesting and Processing, Louisville, USA, 2003; pp.121-130.

[4] Friedman J H. Multivariate adaptive regression splines. Ann Stat, 1991; 19(1): 1-141.

[5] Oktar S, Yüksel S. The banking crisis of the early warning signals: an application on Turkey. Istanbul Commerce University Journal of Social Sciences, 2015; 28: 37-53.

[6] Çinaroğlu S. Examination of random forest performance results generating different number of tress and changing " $\mathrm{k}$ " parameter in cross validation. Turkiye Klinikleri Journal of Biostatistics, 2015; 7(2): 108-118.

[7] Karaköse T, Tekgüler A. Determination of performance characteristics of horizontal wind tunnel in the cleaning of corn-cob mix. Inmateh Journal-Agricultural Engineering, 2017; 53(3): 81-88.

[8] Simonyan K J, Yiljep Y D. Investigating grain separation and cleaning efficiency distribution of a conventional stationary rasp-bar sorghum thresher. Agricultural Engineering International: The CIGR Ejournal, 2008; X: 1-13.

[9] Hamidi O, Tapak L, Abbasi H, Maryanaji Z. Application of random forest time series, support vector regression and multivariate adaptive regression splines models in prediction of snowfall (a case study of Alvand in the middle Zagros, Iran). Theoretical and Applied Climatology, 2018; 134: 769-776.

[10] Taylan P, Weber G W, Özkurt F Y. A new approach to multivariate adaptive regression splines by using Tikhonov regularization and continuous optimization. Top, 2010; 18(2): 377-395.

[11] Hurburgh C R, Bern C J, Brumm T J. Efficiency of rotary grain cleaners in dry corn. Transactions of the ASAE, 1989; 32(6): 2073-2077.

[12] Uhl J B, Lamp B J. Pneumatic separation of grain and straw mixtures. Transactions of the ASAE, 1966; 9: 244-246.

[13] Tabatabaeefar A, Aghagoolzadeh H, Mobli H. Design and development of an auxiliary chickpea second sieving and grading machine. Agricultural Engineering International: CIGR Journal of Scientific Research and Development, 2003; 5: 1-8.

[14] Panasiewicz M, Sobczak P, Mazur J, Zawiślak K, Andrejko D. The technique and analysis of the process of separation and cleaning grain materials. Journal of Food Engineering, 2011; 109: 603-608. 